\title{
Effect of fungal filtrates on germination of wheat grains and the biological control of these fungi using black pepper extract
}

\author{
Fuzia Elfituri Muftah Eltariki, ${ }^{\mathrm{a} b}$, Abdulmajeed Bashir Melitan ${ }^{\mathrm{b}}$, Seok Mui Wang ${ }^{\mathrm{c}}$, Mohammed Abdelfatah \\ Alhoot $^{\mathrm{d}^{*}}$ \\ "Post Graduate Centre (PGC), Management \& Science University (MSU), Shah Alam, Selangor, Malaysia \\ ${ }^{b}$ Department of Botany, Faculty of Science, Misurata University, Misurata, Libya \\ 'Institute for Pathology, Laboratory and Forensic Medicine (I-PPerForM), University Teknologi MARA, Sungai Buloh Campus, Selangor, \\ Malaysia \\ ${ }^{d}$ International Medical School (IMS), Management \& Science University (MSU), Shah Alam, Selangor, Malaysia
}

Received 21st November 2018 / Accepted 23rd July 2019

\begin{abstract}
Wheat is one of the world's most abundant and essential food crops. It covers a significant area of the earth's surface, higher than any other plant, and tends to be among the top strategic crops. Wheat contamination with fungi leads to rapid deterioration of quantity and quality of wheat products. Many of those fungi are potential mycotoxins producers. This study aimed to isolate and identify fungi that contaminating the wheat grains from the Misurata Agricultural Research Center area and the South Region of Libya. Fungi contaminating wheat grains were isolated on Potato Dextrose Agar (PDA) and identified by culture characteristics and microscopically. Fungal filtrates of two fungal isolates, Aspergillus niger and Rhizopus sp., were tested for their effects on the germination and seedlings of wheat grains. Furthermore, the effect of acetonic extracts of Black pepper (Piper nigrum) on the growth of the isolated fungi was also investigated. Ten types of fungi belonging to four genera were isolated and identified. The germination rate of wheat grains irrigated with the filtrate of $A$. niger and Rhizopus sp. was $20 \%$ and $80 \%$ respectively, compared with $100 \%$ of the control grains, which were irrigated with water. The culture filtrates of both A. niger and Rhizopus sp. affect not the only percentage of grains germination but also the morphology of wheat seedlings. It adversely affected the length of the radicles and coleoptiles. The acetone extract of $P$. nigrum showed inhibitory effect $(85.7 \% \pm 3.7$ and $44.0 \% \pm 3.1)$ on the germination of $A$. niger and Rhizopus sp. respectively. This study concludes that fungal secretions have pathogenic effects on plant growth, which can lead to potential health risks for the human population. Biological control such as Piper nigrum extracts can be an alternative to chemical pesticides for controlling fungal pathogens and their secretions.
\end{abstract}

Keywords: wheat grains, Aspergillus, Rhizopus, Piper nigrum, germination, biological control

\section{INTRODUCTION}

Wheat is one of the most important food crops in the world. It contains carbohydrate $(70 \%)$, protein $(12 \%)$ and fat $(29 \%)$, providing about $20 \%$ of the calories in human food worldwide (Putnam et al., 2002). Wheat grains are exposed to various fungal contaminations starting from the time of physiological maturity until they are used for either agriculture or consumption. More than 100 fungal species have been found contaminating the grains. Some of these fungi

*Author for correspondence: Mohammed Abdelfatah Alhoot, International Medical School (IMS), Management \& Science University (MSU), Shah Alam, Selangor, Malaysia. Email - malhoot@hotmail.com 
have potential risks to plants grown from these grains, while others can cause problems of decay and release of toxins during storage that has a potential threat to the consumers' health (Kabak et al., 2006; Kent \& Evers, 1994). The safety of grains is essential for its use in agriculture, storage, and consumption. Hence, wheat grains should be stored in a proper condition which contains suitable moisture (not exceed 12\%), absent of contaminants, residues or harmful substances, grain fracture percentage is not more than $2 \%$, and should be of the same size, color, and smell. The storage conditions should be as appropriate as possible to maintain good grain quality (LopezGarcia \& Park, 1998).

Wheat grains show the symptoms of deformation, discoloration, or black spots caused by some fungi in the field when the humidity is high (>90\%). The most common fungi associated with these symptoms include Alternaria sp., Fusarium sp., Cladosporium sp., Aspergillus sp., Penicillium sp., and Rhizopus sp. (Bhale et al., 2001). Fungal contamination of soybean seeds with Aspergillus, Penicillium, and Rhizopus has shown to cause reduction of germination rate and defected of seedling during field plantation (Anwar, 1995; Ibrahim, 2015).

Black pepper (Piper nigrum) is one of the wellknown medicinal plants that have prominent roles in pharmaceutical, industrial and agricultural production. It contains active antimicrobial substances, aromatic oils, phenols, aldehydes, and alkaloids. These substances are used in food maintenance, formulation of pharmaceuticals and alternatives to medicines and natural remedies (Jafeer \& Kheirallah, 2017; Ody, 2017). P. nigrum is a flowering vine of the Piperaceae. It is cultivated for its fruit which is usually dried and used as a spice and seasoning that are known as a peppercorn. When fresh and fully mature, it is dark red and contains a single seed. Peppercorns and the ground pepper derived from them may be described just like pepper, or more precisely as black pepper (cooked and dried unripe fruit), green pepper (dried unripe fruit), and white pepper (ripe fruit seeds). Black pepper is native to Kerala in Southwestern India (Hajeski, 2016; Sen, 2004) and is extensively cultivated there and elsewhere in tropical regions. Vietnam is the world's largest producer and exporter of pepper, producing $34 \%$ of the world's $P$. nigrum crop as of 2013 (Yogesh \& Mokshapathy, 2013).

Fungi of the genera Aspergillus, Fusarium, Penicillium, and Rhizoctonia are known to produce toxic metabolites which are known as mycotoxins (Eltariki et al., 2018). These mycotoxins had been reported to degrade seed quality and reduce their viability (Magan \& Aldred, 2007; MohamedYasseen et al., 1994). The fungistatic or fungicidal effect of spices is due to the inhibitory action of natural products, and the mechanisms involved are cytoplasm granulation, cytoplasmic membrane rupture, and inactivation and/or inhibition of intracellular and extracellular enzymes. These biological events could take place separately or concomitantly culminating with mycelium germination inhibition and it is also reported that plant lytic enzyme act in the fungal cell wall causing breakage of $\beta-1,3$ glycan, $\beta-1,6$, glycan, and chitin polymer (Pundir \& Jain, 2010). Historically, it has been thought to cure many illnesses, such as cancer, malaria, cholera, nausea, fever, migraine headaches, poor digestion, strep throat, and even coma. Piperine is an alkaloid found naturally in plants belonging to the pyridine group of family Piperaceae, such as $P$. nigrum and contains some of the antimicrobial components such as Terpinene, $\alpha$-pinene, $\beta$-pinene, Linaleol and Terpineol, Piperine, pipene, piperamide and piperamine it has to possess diverse pharmacological activities. Piperine has been found to enhance the therapeutic efficacy of many drugs, vaccines, and nutrients by increasing oral bioavailability by inhibiting various metabolizing enzymes. There is preclinical evidence that it may have modest immune system enhancing properties (Kaho et al., 2019).

Culture filtrates of Aspergillus sp. have reported in causing a reduction in seed germination and root-shoot elongation (Jalander \& Gachande, 2012). Seed-borne diseases play a significant role in the quantity and quality of the agricultural product. Seed rot, seedling blight, Bipolaris leaf spot, and Cuvularia leaf spot are etiologically caused by Penicillium sp., Fusarium oxysporium, Aspergillus sp., Bipolaris maydis, and Curvularia lunata respectively (Debnath et al., 2012).

This study aimed to identify the fungal species contaminating the wheat grains in Libya and to investigate the effect of isolated fungi filtrates on 
grains germination rate and seedling development. Furthermore, the inhibition effect of $P$. nigrum (black pepper) extract on the growth of isolated toxigenic and pathogenic fungi will also be evaluated.

\section{MATERIALS AND METHOD}

\section{Sample collection}

Wheat grain samples were collected from Misurata Agricultural Research Center area and South Region of Libya. Three samples for each type of wheat, Triticum aestivum cv. and the solid wheat cultivar Triticum durum cv., were collected randomly from stored grains in each area and transported to laboratory using properly sealed sterile polythene bags. The samples were kept at $4^{\circ} \mathrm{C}$ until fungal cultivation, isolation, and identification were carried out as described previously (Fente et al., 2001; Sekar et al., 2008).

\section{Isolation and identification of fungi on wheat grains}

Fungi carried on wheat grains were isolated on Potato Dextrose Agar (PDA) as previously described (Fente et al., 2001; Sekar et al., 2008). The wheat grains used for culture was randomly selected from the samples and picked up using sterile forceps. Grain seeds were washed aseptically with $10 \mathrm{~mL}$ of sterile distilled water. PDA media were prepared, and chloramphenicol $(500 \mathrm{mg} / \mathrm{L})$ was added to inhibit bacterial growth. Five grains of wheat were inoculated on each culture media plate with equal distribution. The grains were immersed in the agar to ensure that the grain surface is directly contacted with the nutrient in the medium. Three replicates were maintained for each sample. After inoculation, all dishes were incubated in the incubator at a temperature of $25^{\circ} \mathrm{C}$ for seven days. Culture plates were checked daily for growth and sporulation. After seven days of incubation, the different fungal colonies were sub-cultured into fresh PDA plates. The isolated fungi were identified based on colony morphology and microscopic characteristics using an optical microscope according to the following references (Domsch et al., 2007; Ebrahim, 1998; Nelson et al., 1983).

\section{Effect of fungal filtrates on germination of wheat grains and seedling growth}

Potato Dextrose Broth (PDB) was prepared under septic conditions to prepare the fungal filtrates of isolated fungi from wheat grains were prepared under septic conditions using Potato Dextrose Broth (PDB). These filtrates were prepared from 3 - 4 days sub-cultured $A$. niger and Rhizopus sp. on PDA. A piece of $9 \mathrm{~mm}$ in diameter of PDA for each fungal isolate was inoculated in a flask containing $25 \mathrm{~mL}$ PDB. Three sets of three flasks were assigned for $A$. niger, Rhizopus sp., and control (Garuba et al., 2014; Hajieghrari, 2010) (Figure 1). The control flasks were inoculated with PDA only. After the inoculation, all flasks were incubated in the incubator at $25^{\circ} \mathrm{C}$. Ten days later, the flasks were removed from the incubator, and the media was separated from the growth by filtration using sterile filter paper (Whatman glass microfiber filter paper Grade GF/F Retention 0.7 Micron).

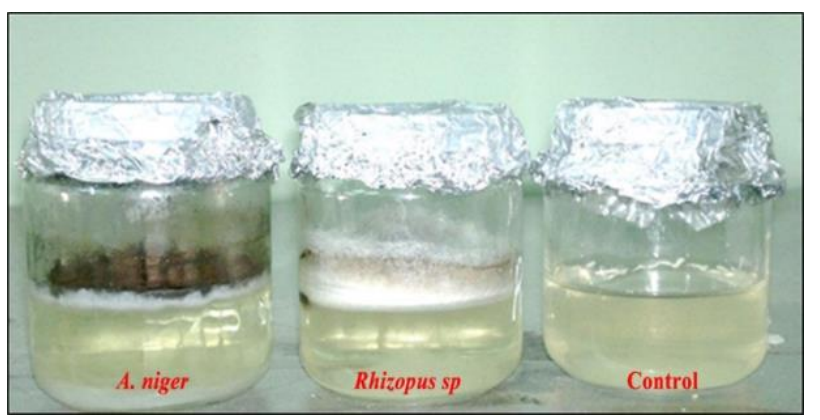

Figure 1. Growth of $A$. niger and Rhizopus sp. on Potato Dextrose Broth.

In order to investigate the effect of fungal filtrates on the germination and growth of seedling of wheat grains, several clean and sterilized Petri dishes were prepared with sterilized filter paper. In each dish, five grains of wheat were sterilized with $0.1 \%$ hydrogen peroxide solution, and the grains were irrigation with $10 \mathrm{~mL}$ of the filtration. Three dishes containing the same number of wheat grains were used for each type of the filtrations. Two control plates were included in which one was irrigated with PDB, and another one was irrigated with sterile distilled water. All dishes were incubated in the incubator at $25^{\circ} \mathrm{C}$. All plates were examined for the growth of grains on day three, five, seven, and ten. The percentage of germination was calculated according to the following equation: 
Inhibition ratio $(\%)=\frac{\text { Untreated colony diameter-Treated colony diameter }}{\text { Untreated colony diameter }} \times 100$

\section{Statistical analysis}

Statistical analysis was done using Graph Pad Prism version 5.01 (Graph Pad Software, USA). P values of $<0.05$ were considered significant. Error bars were expressed in the graphs as \pm SD.

\section{RESULTS AND DISCUSSION}

\section{Isolation and identification of fungi on wheat grains}

It emerged from the current study that wheat grains obtained from the different production area were found to be contaminated with many types of fungi. A total of 319 colonies were isolated from wheat grains, of which 213 colonies were isolated from the Misurata Agricultural Research Center area, and 106 colonies were from the South Region of Libya. Table 1 shows that the number of colonies isolated from wheat grains from Misurata Agricultural Research Center area is more than the number of colonies isolated from the South Region of Libya. This variation in the number of colonies may be due to the Misurata Agricultural Research Center area has a moderate and humid climate during the sapling time, allowing the moisture-loving fungus and temperate fungi to have a more extended period of growing and reproduction for several generations, and thus producing a large number of germs. In contrary, the South Region of Libya is known for its relatively dry hot climate which could provide a short period of fungi on the cultivated grains to grow and reproduce during the time of the spikes production and consequently resulting in the decrease of production of germs. The results showed that Fusarium was predominant in wheat grains from southern Libya, which could be because the desert soils containing more Fusarium (Zeller et al., 2003). This fungus also can tolerate adverse conditions such as high temperatures and drought for long periods in the form of chlamedospores (Agrios, 2012; Cook, 1981). Furthermore, its dense presence in the desert soils, especially when cultivating sensitive species, contributes and increases the seriousness of the injury of plants at different stages which has negatively affects the quality and quantity of the crop (Zeller et al., 2003).

Table 1. The number of fungal colonies isolated from wheat grains obtained from Misurata Agricultural Research Center area and South Region of Libya.

\begin{tabular}{ccc}
\hline Isolated Fungi & $\begin{array}{c}\text { Misurata } \\
\text { Agricultural } \\
\text { Research } \\
\text { Center area }\end{array}$ & $\begin{array}{c}\text { South } \\
\text { Region of } \\
\text { Libya }\end{array}$ \\
\hline Aspergillus sp. & 10 & - \\
Aspergillus sp1 & 2 & - \\
Aspergillus sp2 & 6 & - \\
Aspergillus sp3 & 4 & - \\
Aspergillus niger & 10 & - \\
Rhizopus sp. & 50 & - \\
$\begin{array}{c}\text { Fusarium sp. } \\
\text { Fusarium sp1 }\end{array}$ & - & 60 \\
Fusarium oxysporum & 43 & 45 \\
Penicillium sp1 & 41 & - \\
$\begin{array}{c}\text { Penicillium } \\
\text { chrysogenum }\end{array}$ & 35 & 1 \\
\hline $\begin{array}{c}\text { Total number of } \\
\text { colonies }\end{array}$ & 12 & - \\
Total number of \\
species
\end{tabular}

Morphological identification of fungal species was made using macroscopic and microscopic characterization. For fungi isolated from Misurata Agricultural Research Center area, ten species belonged to four genera, which are Aspergillus niger, Aspergillus sp., Aspergillus sp1, Aspergillus sp2, Aspergillus sp3, Rhizopus sp, Fusarium oxysporum, Fusarium sp1, Penicillium chrysogenum, and Penicillium sp1. Three fungal species belonged to two different genera which are Penicillium sp1, Fusarium sp1, and Fusarium sp were isolated from the South Region of Libya. Aspergillus niger and Rhiropus sp. (Figure 2) were the most common species isolated from wheat grains in both geographical areas. Thus, these genera were selected to investigate the effect of fungal filtrates on germination of wheat grains and seedling growth. These fungi were isolated from the grains and identified in Assiut University, Egypt. 


\section{Effect of fungal filtrates on germination rate of wheat grains and seedling growth}

Wheat grains could be contaminated with fungi either in the field or during storage and exhibition in the markets. These fungi are likely to grow and produce toxins that may affect the vitality of the wheat grains. The role of fungal secretion on germination rates and development of seedlings of wheat grains has run out in this study. A. niger and Rhizopus sp. filtrates reduced the rate of germination after ten days to $20 \%$ and $80 \%$ respectively compared to germination rate of $100 \%$ for grains irrigated with distilled water as shown in Table 2 and Figure 3. This result was supported by a previous study, (Ibraheem et al., 1987) which found that $A$. niger, A. flavus, and Alternaria alternata had an inhibitory effect of reducing seed germination. These results are also consistent with many previous studies. Khokhar et al. reported that $P$. chrysogenum decreased the percentage of seed germination by $20.33 \%$. This fungus had shown a poisoning effect on the seedling of cereal as evidenced in inhibition of the seed germination percentage of wheat at a higher percentage of $90 \%$ (Khokhar et al., 2013). The inhibition may indicate that the tested fungi produce toxic metabolites in the broth which they were cultured. $A$. niger and $P$. chrysogenum produced metabolites which are known to reduce germination and seedling development (Haikal, 2008). A. niger can produce mycotoxins such as oxalic acid crystals, kojic acid, and malformins depending on the growth condition and the strain of the organism (Garuba et al., 2014). This effect varies with different fungi.

Grains irrigated with $A$. niger filtrate showed a significant reduction of the radicle lengths $(98.3 \%$ $\pm 0.6,97.8 \% \pm 0.5,97.8 \% \pm 0.2$ and $97.8 \% \pm 0.0$ ) after three, five, seven and ten days respectively.
This reduction rate is statistically significant when compared with irrigated grains with water (TwoWay ANOVA with Bonferroni post-test, $\mathrm{P}<$ 0.001), as shown in Figure 4. Again, grains irrigated with Rhiropus sp. filtrate showed a reduction of the radicle lengths $(63.4 \% \pm 3.7$, $64.6 \% \pm 4.6,66.3 \% \pm 4.2$ and $67.4 \% \pm 10.8)$ after three, five, seven and ten days respectively. This reduction rate is statistically significant when compared with irrigated grains with water (TwoWay ANOVA with Bonferroni post-test, $\mathrm{P}<$ 0.001) as shown in Figure 4. Similarly, the coleoptile lengths of grains irrigated with $A$. niger and Rhizopus sp. filtrates were also significantly shorter compared to grains irrigated with water (Two-Way ANOVA with Bonferroni post-test, P $<0.001)$ as shown in Figure 5. Grains irrigated with $A$. niger filtrate showed $(93.9 \% \pm 1.5,95.5 \%$ $\pm 0.6,95.3 \% \pm 0.3$ and $94.7 \% \pm 1.9$ ) reduction of the coleoptile lengths after three, five, seven and ten days respectively. Also, grains irrigated with Rhizopus sp. filtrate showed (43.5\% $\pm 19.9,43.2 \%$ $\pm 1.5,36.0 \% \pm 4.4$ and $29.9 \% \pm 4.7)$ reduction of the coleoptile lengths after three, five, seven and ten days respectively. These results are consistent with the finding of the previous study (Garuba et al., 2014). This study showed $65.33 \%$ and $79.67 \%$ germination ratio of corn seeds due to the effect of $A$. niger and Penicillium chrysogenum filtrates, respectively, when compared with control.

Table 2. Effect of fungal on wheat grain germination.

\begin{tabular}{cc}
\hline Fungal filtrates & $\begin{array}{c}\text { Germination rate after } \\
\mathbf{1 0} \text { days }\end{array}$ \\
\hline A. niger & $20 \%$ \\
Rhizopus sp. & $80 \%$ \\
Control (PDA) & $98 \%$ \\
Control (Water) & $100 \%$ \\
\hline
\end{tabular}

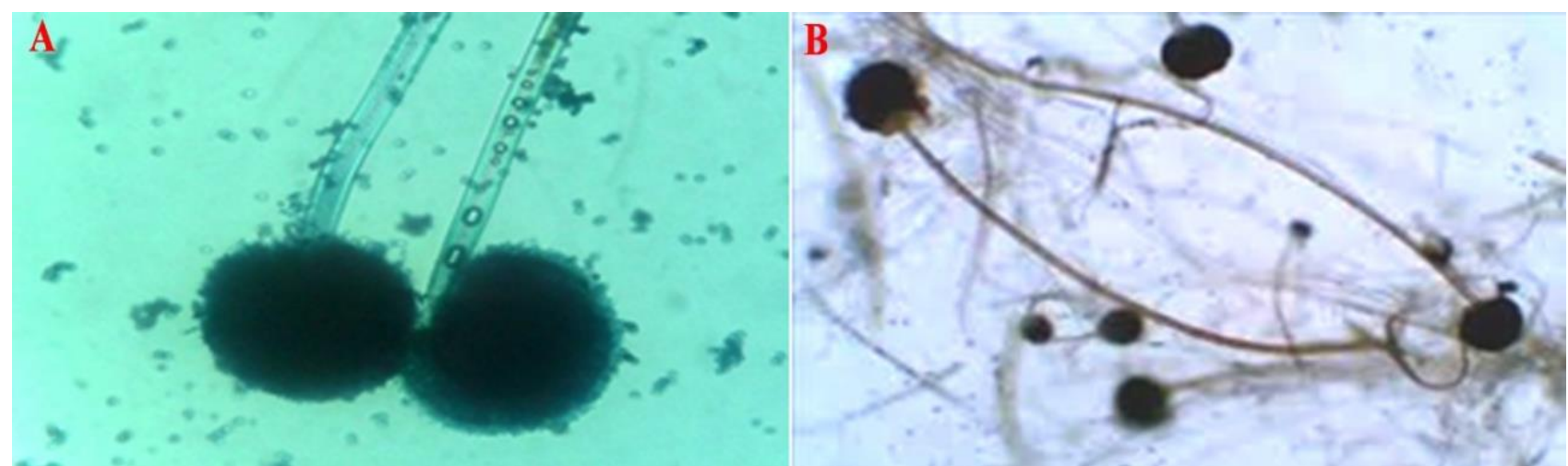

Figure 2. Microphotographs of fungal species isolated from wheat grains. (A) A. niger, (B) Rhizopus sp. 


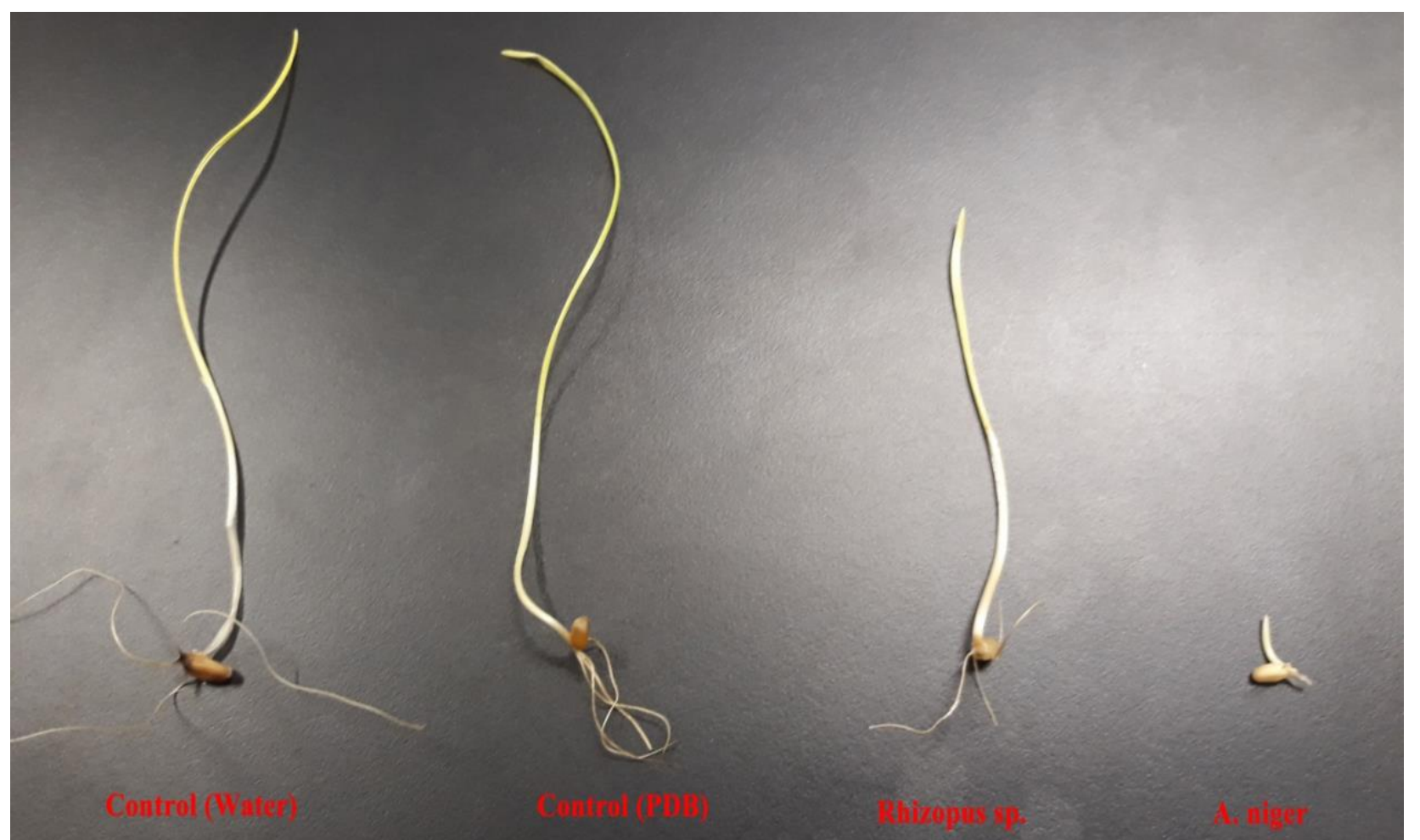

Figure 3. Effect of fungi filtrates on the wheat grains germination and growth of seedlings after 10 days.

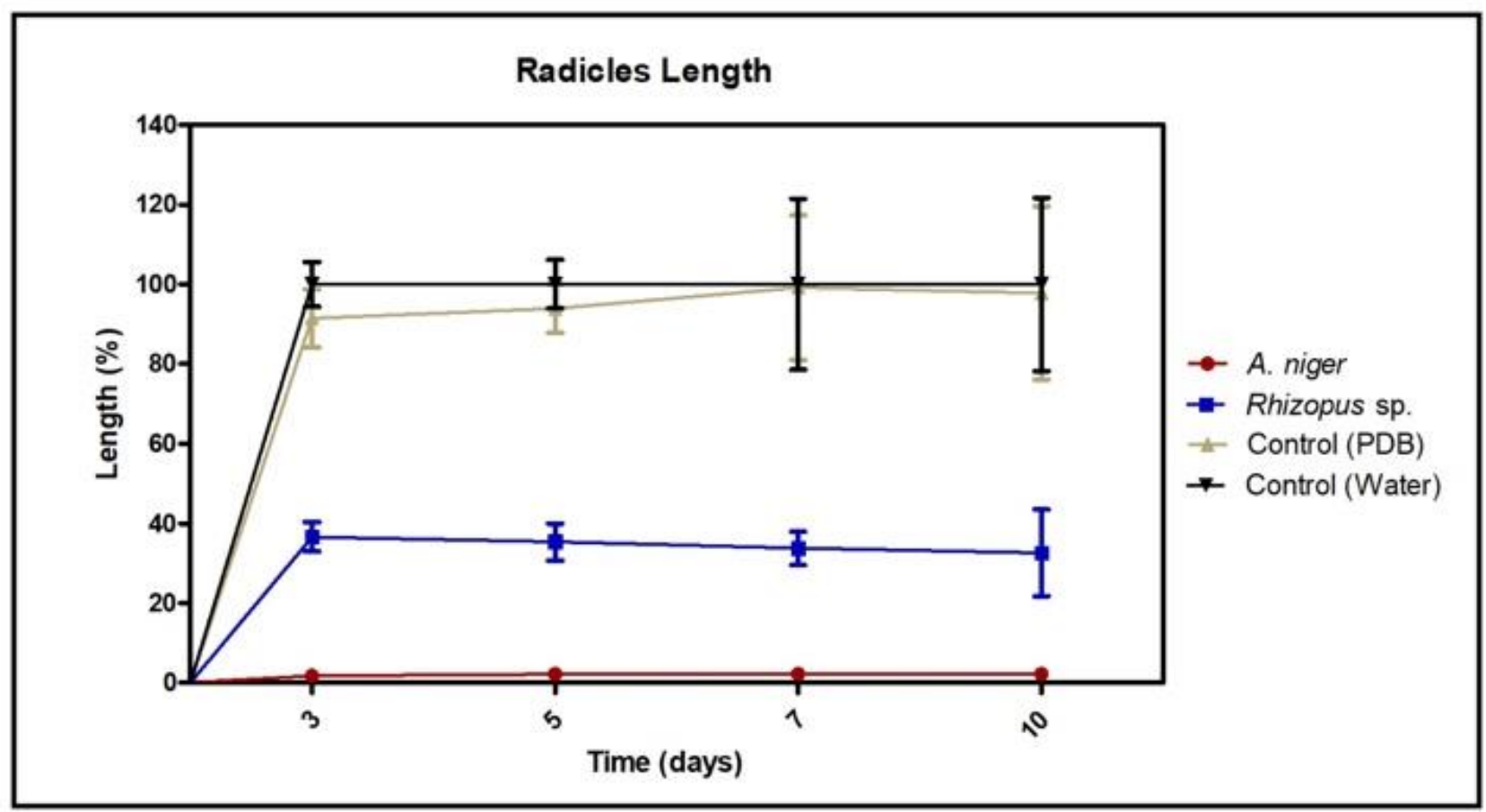

Figure 4. Effect of $A$. niger and Rhizopus sp. filtrates on the length of wheat radicles. A significant reduction of radicle lengths was observed when compared with grains irrigated with PDB and water (TwoWay ANOVA with Bonferroni post-test, $\mathrm{P}<0.001)$. Results are expressed as mean $\pm \mathrm{SD}$ from a representative experiment performed in triplicate. 


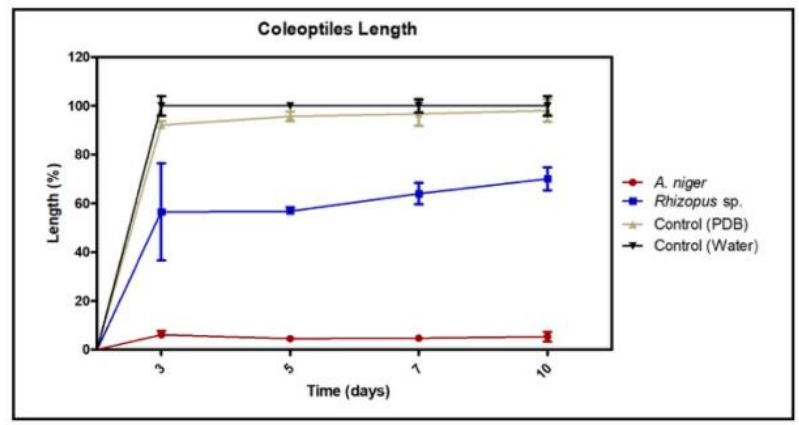

Figure 5. Effect of $A$. niger and Rhiropus sp. filtrates on the length of wheat coleoptiles. A significant reduction of coleoptile lengths was observed when compared with grains irrigated with PDB and water (Two-Way ANOVA with Bonferroni post-test, $\mathrm{P}<0.001)$. Results are expressed as mean \pm SD from a representative experiment performed in triplicate.

Results reported that $A$. niger filtrate has a more adverse effect on the germination rate of wheat grains and the development of their seedings. It could be due to the ability of the fungus to produce Aflatoxins. These findings are consistent with previous findings (Garuba et al., 2014; Jeswal, 1987; Tewfik et al., 1974) that concluded that Aflatoxins prevent or reduce the rate of germination of many crop seeds. It reduces the growth of the crop seedling as well as the development of the radicles and coleoptiles produced from irrigated grains.

Results also showed that Rhizopus sp. has a mild deleterious effect on wheat grain germination, seedling development, and evolution of the radicles and coleoptiles compared to $A$. niger which can be referred due to the differences in substrates and chemical quality from the toxins produced by $A$. niger. These toxins can also inhibit the naturally occurring Gibberellins produced by the embryo during germination leading to a shortening of the radicles and coleoptiles (Jones \& Armstrong, 1971; Sinha, 1996).

\section{Evaluation of the effect of $P$. nigrum (black} pepper) extract on the growth of isolated fungi. The acetonic extract of $P$. nigrum showed significant inhibition effect on the growth of isolated fungi, $A$. niger and Rhizopus sp., from wheat grains, as shown in Figure 6 and Figure 7. The Inhibition rate of the treated fungal cultures with extract of $P$. nigrum were $85.7 \% \pm 3.7$ and $44.0 \% \pm 3.1$ for $A$. niger, and Rhiropus sp. respectively compared to untreated control (Paired t-tests with two-tailed, $\mathrm{P}<0.001)$. The inhibition effect of $P$. nigrum extract on $A$. niger and Rhiropus sp. may be due to it contains active compounds such as saponins, phenols, and alkaloids. It is known that these compounds have a powerful effect on many pathogens (Agrios, 2012; Gülçin, 2005; Pundir \& Jain, 2010). The result of this study is consistent with previously published results (Abdel Mohsen, 2011). Many plant extracts, including black pepper, showed protection of sunflower plant from decay by Macrophomina phaseolina. These plants reduce the fungal infection rate by $53.1 \%$. This inhibition by chili extract could be due to the presence of alkaloids capsorubin, dihgdro, capsiain, and capsiacin. This inhibition is also consistent with another study which showed the inhibition of the growth of pathogenic fungi, namely Cocblibeolas migabeanus, Pyricularia oryzae, and Rhizoctonia solani in rice (Tewari \& Nayak, 1991).
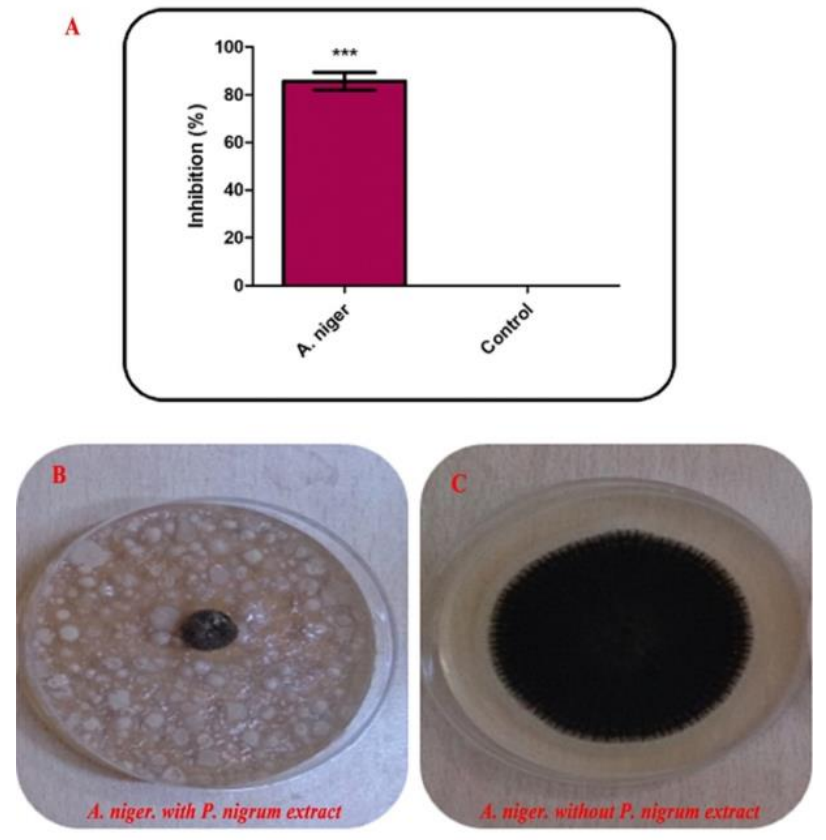

Figure 6. Effect of $P$. nigrum extract on $A$. niger growth. (A) shows significant inhibition effect on the growth of isolated $A$. niger (Paired t-tests with two-tailed, $\mathrm{P}<0.001)$. Results are expressed as mean \pm SD from a representative experiment performed in triplicate. The asterisk denotes the level of statistically significant differences from the untreated control. (B) shows colony morphology of $A$. niger treated with $P$. nigrum. (c) shows colony morphology of $A$. niger untreated with $P$. nigrum. 
A
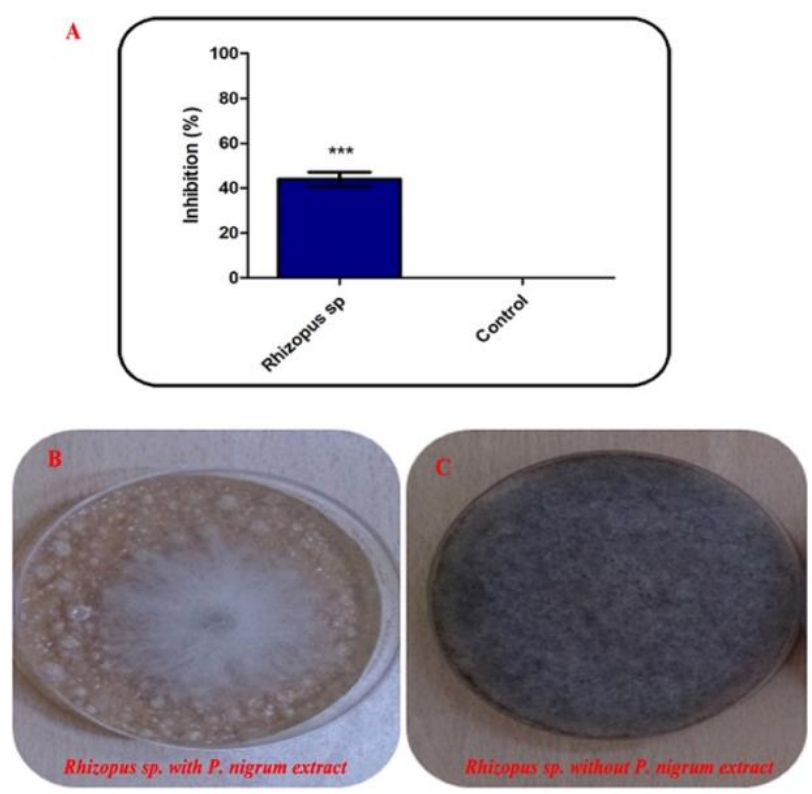

Figure 7. Effect of P. nigrum extracts on Rhizopus sp. growth. (A) shows significant inhibition effect on the growth of isolated Rhizopus sp. (Paired ttests with two-tailed, $\mathrm{P}<0.001)$. Results are expressed as mean \pm SD from a representative experiment performed in triplicate. The asterisk denotes the level of statistically significant differences from the untreated control. (B) shows colony morphology of Rhiropus sp. treated with $P$. nigrum. (C) shows colony morphology of Rhiropus sp. untreated with P. nigrum.

\section{CONCLUSION}

The metabolic products of $A$. niger and Rhizopus sp impair the germination and growth rate of wheat and therefore diminishing its quality, especially the stored wheat grains. Hence necessity should be placed on these fungi and their metabolic processes due to their adverse effects on agriculture, health, and industry. Further studies on the biological control of fungi should be encouraged using other types of plants. The active compounds in these plants have the potential to be an effective antifungal agent.

\section{ACKNOWLEDGEMENT}

We would like to acknowledge the Management and Science University (MSU) for funding this project under University Seed Grant Number: SG-376-0216-IMS. The funders had no role in the study design, data collection, and analysis, decision to publish, or preparation of the manuscript. Thanks, are addressed to Misurata University, Misurata, Libya, and Misurata Agricultural Research Center for their cooperation in providing the essential information to complete this study.

\section{REFERENCES}

Abdel Mohsen, H. A. -J. 2011. Test the efficiency of some plant powders in the protection of the sun flower plant from the infection of the fungus Macrophomia phaseolina (tassi) Goid, which causes the disease. Faculty of Agriculture, University of Basra, 3(2).

Agrios, G. N. 2012. Plant Pathology. Elsevier.

Al-Jawhari, I. F. 2012. The effect of acetonic extracts on some plants on the associated mushrooms of barley seeds in Misurata City, Faculty of Education, Department of Life Sciences. Journal of Agricultural Research: 1(2).

Al Fadl, F. \& Al Haidari, F. 2012. Effect of leachates isolated from rice residues on wheat grain germination and growth of Fusarium graminearum and Rhizoctonia solani nurses and Trichoderma harzianum. Department of Plant Protection Faculty of Agriculture - University of Kufa Iraq.

Anwar, S. A., Abbas , S. F., Gill , M. M., Rauf , C. A., Mahmood, S., \& and Bhutta , A. R. 1995. Seed borne fungal soyabean and their effect on seed germination. Pakistan Journal of Phytopathology 7(2): 184-190.

Bhale, M. S., Khare, D., Raut, N., \& Dharam, S. 2001. Seed-borne diseases objectionable in seed production and their management. Scientific Publisher, India.

Cook, R. J. 1981. Fusarium diseases of wheat and other small grains in North America. Fusarium Diseases, Biology, and Taxonomy: 39-52.

Debnath, M., Sultana, A., \& Rashid, A. 2012. Effect of seed-borne fungi on the germinating seeds and their bio-control in maize. Journal of Environmental Science and Natural Resources 5(1): 117-120.

Domsch, K. H., Gams, W., \& Anderson, T. -H. 2007. Compendium of soil fungi. 2 ed. IHW-Verlag, Germany.

Ebrahim, M. 1998. Environmental and physiological studies on some of the fungus-borne fungi of wheat and barley grains in Misurata region and their effect on germination and seedling development. Master Thesis, Faculty of Science, Nasser University, Libya.

Eltariki, F. E. M., Tiwari, K., Ariffin, I. A., \& Alhoot, M. A. 2018. Genetic Diversity of Fungi Producing Mycotoxins in Stored Crops. Journal of Pure and Applied Microbiology 12(4): 18151823.

Fente, C., Ordaz, J. J., Vazquez, B., Franco, C., \& Cepeda, A. 2001. New additive for culture media for rapid identification of aflatoxin-producing Aspergillus strains. Applied and Environmental Microbiology 67(10): 4858-4862.

Garuba, T., Abdulrahaman, A., Olahan, G., Abdulkareem, K., \& Amadi, J. 2014. Effects of fungal filtrates on seed germination and leaf anatomy of maize seedlings (Zea mays L., Poaceae). Journal of Applied Sciences and Environmental Management 18(4): 662-667. 
Gülçin, İ. 2005. The antioxidant and radical scavenging activities of black pepper (Piper nigrum) seeds. International journal of Food Sciences And Nutrition 56(7): 491-499.

Haikal, N. Z. 2008. Effect of filtrates of pathogenic fungi of soybean on seed germination and seedling parameters. Journal of Applied Sciences Research 4(1): 48-52.

Hajeski, N. J. 2016. National Geographic Complete Guide to Herbs and Spices: Remedies, Seasonings, and Ingredients to Improve Your Health and Enhance Your Life. National Geographic Society.

Hajieghrari, B. 2010. Effects of some Iranian Trichoderma isolates on maize seed germination and seedling vigor. African Journal of Biotechnology 9(28): 4342-4347.

Ibraheem, S., Okesha, A., \& Mhathem, K. 1987. Interrelationship between protein and oil content of soybean seed with some associated fungi. Journal of Agriculture and Water Resources Research, Plant Production 6(2): 53-66.

Ibrahim, M. A. O. 2015. Detection and identification of some seed borne fungi of groundnut from different locations with emphasis on Aspergilus flavus and its control in Sudan, Sudan University of Science and Technology.

Jafeer, K. A. -M. M., \& Kheirallah, E. A. 2017. Effect of Piper Nigrum fruit and Syzygium aromaticum roses extract on the some of bacterial and fungal isolate growth. Al-Qadisiyab Journal of Pure Science 21(2).

Jalander, V. \& Gachande, B. 2012. Effect of fungal metabolites of some rhizosphere soil fungi on seed germination and seedling growth of some pulses and cereals. Journal of Scientific Research and Reports 2: 265-267.

Jeswal, P. 1987. Effect of aflatoxin B1, on germination and seedling growth of maize. National Academy Science Letters 10: 79-82.

Jones, R. \& Armstrong, J. 1971. Evidence for osmotic regulation of hydrolytic enzyme production in germinating barley seeds. Plant Physiology 48(2): 137-142.

Kabak, B., Dobson, A. D., \& Var, I.L. 2006. Strategies to prevent mycotoxin contamination of food and animal feed: a review. Critical Reviews in Food Science and Nutrition 46(8): 593619.

Kaho, Z. M., Kadum, A. R., \& Hadi, A. A. 2019. evalution of antibacterial activity of Piper nigrum extract against Streptococcus mutans and Escherichia coli. Journal of Pharmaceutical Sciences and Research 11(2): 367-370.

Kent, N. L. \& Evers, A. D. 1994. Kent's Technology of Cereals: An introduction for students of food science and agriculture. 4 ed. Elsevier Science Ltd.

Khokhar, I., Haider, M. S., Mukhtar, I., Ali, A., Mushtaq, S., \& Ashfaq, M. 2013. Effect of Penicillium species culture filtrate on seedling growth of wheat. International Research Journal of Agricultural Science and Soil Science 3(1): 24-29.

Lopez-Garcia, R. \& Park, D. L. 1998. Effectiveness of post-harvest procedures in management of mycotoxin hazards. Mycotoxins in Agriculture and Food Safety (Bhatnagar D, Sinha S, eds). New York: Marcel Dekker, 407-433.

Magan, N. \& Aldred, D. 2007. Post-harvest control strategies: minimizing mycotoxins in the food chain. International Journal of Food Microbiology 119(1-2): 131-139.

Mohamed-Yasseen, Y., Barringer, S. A., Splittstoesser, W. E., \& Costanza, S. 1994. The role of seed coats in seed viability. The Botanical Review 60(4): 426-439.

Nelson, P. E., Toussoun, T. A., \& Marasas, W. 1983. Fusarium species: an illustrated manual for identification. Pennsylvania State University Press, USA.

Ody, P. 2017. The Complete Medicinal Herbal: A Practical Guide to the Healing Properties of Herbs. Skyhorse.

Pundir, R. K. \& Jain, P. 2010. Comparative studies on the antimicrobial activity of black pepper (Piper nigrum) and turmeric (Curcuma longa) extracts. International Journal of Applied Biology and Pharmaceutical Technology 1(2): 492-500.

Putnam, J., Allshouse, J., \& Kantor, L. S. 2002. US per capita food supply trends: more calories, refined carbohydrates, and fats. Food Review 25(3): 2-15.

Sekar, P., Yumnam, N., \& Ponmurugan, K. 2008. Screening and characterization of mycotoxin producing fungi from dried fruits and grains. Advances in Biotechnology 7(1): 12-15.

Sen, C. T. 2004. Food culture in India. Greenwood publishing group.

Sinha, K. 1996. Mycotoxin induced physiological responses in crop plants. MD Publications Pvt. Ltd.

Tewari, S. \& Nayak, M. 1991. Activity of four plant leaf extracts against three fungal pathogens of rice. Tropical Agriculture 68(4): 373-375.

Tewfik, M., El-Khadem, M., \& Hamdi, Y. 1974. Partial purification of aflatoxins by simple chemical fractionation. Zentralblatt für Bakteriologie, Parasitenkunde, Infektionskrankheiten und Hygiene. Zweite Naturwissenschaftliche Abteilung: Allgemeine, Landwirtschaftliche und Technische Mikrobiologie 129(3-4): 225230.

Yogesh, M. \& Mokshapathy, S. 2013. Production and export performance of black pepper. International Journal of Humanities and Social Science Invention 2(4): 36-44.

Zeller, K. A., Summerell, B. A., Bullock, S., \& Leslie, J. F. 2003. Gibberella konza (Fusarium konzum) sp. nov. from prairie grasses, a new species in the Gibberella fujikuroi species complex. Mycologia 95(5): 943-954. 